\title{
MECANISMOS DE CONTROLE EM UMA PROPOSTA : NARRATIVA DO LIVRO DIDÁTICO DE LÍNGUA PORTUGUESA E EFEITOS DA ROTEIRIZAÇÁO
}

\author{
Adriana Oliveira de Farias*1 \\ Janima Bernardes Ribeiro** \\ Sulemi Fabiano Campos***
}

\section{RESUMO}

Este artigo objetiva investigar os efeitos que os mecanismos de controle em uma proposta narrativa do livro didático de língua portuguesa (LDP), do $6^{\circ}$ ano, provocam nos textos dos alunos. Toma como corpus uma proposta narrativa do livro didático Português: Linguagem (CEREJA; MAGALHÃES, 2006). Traz como pressupostos teóricos Althusser (1985), que considera a escola como parte dos Aparelhos Ideológico do Estado (AIE) e Geraldi (2010, 2011) acerca da prática de produção textual. Os resultados apontaram que a atividade narrativa proposta pelo LDP com os roteiros, as instruções e até desenhos, quando aplicada sem a mediação do professor no processo de escrita do aluno, resultaram na homogeneização dos textos. Desse modo, este estudo contribui para compreender melhor os problemas e as dificuldades que envolvem o processo de ensino e aprendizagem da produção textual escrita no contexto escolar e também reafirma a necessidade de aperfeiçoamento da prática docente no contexto escolar.

PALAVRAS-CHAVE: Livro didático. Proposta narrativa. Mecanismos de controle. Efeitos da roteirização

\footnotetext{
1 *Mestre em Letras pelo Mestrado Profissional em Letras (Profletras) da UFRN. adrianaport99@, hotmail.com

** Doutoranda em Estudo da Linguagem - PPgEL/UFRN, integrante do Grupo de Estudo do Texto e do Discurso - GETED. janimabernardesribeiro@yahoo.com.br

*** Professora Doutora do Departamento de Letras e do Programa de Pós-Graduação em Estudos da Linguagem da Universidade Federal do Rio Grande do Norte. Líder do Grupo de Pesquisa em Estudos do Texto e do Discurso/GETED e integrante do Grupo de Estudos e Pesquisa Produção Escrita e Psicanálise - GEPPEP/USP. sulemifabiano@yahoo.com.br
} 


\section{INTRODUÇÃO}

Este trabalho é um recorte de duas pesquisas ${ }^{2}$ realizadas no âmbito dos trabalhos desenvolvidos no Grupo de Pesquisa em Estudos do Texto e do DiscursoGETED/UFRN. Na primeira pesquisa, investigamos os mecanismos de controle do trabalho escolar apresentados nos LDP nos exercícios de escrita direcionados à prática do professor e ao fazer do aluno em situações de ensino, e na segunda pesquisa, os efeitos que a roteirização presente na atividade provocou na produção do texto narrativo dos alunos. No presente estudo, temos como objetivo central investigar os efeitos que os mecanismos de controle provocam nos textos dos alunos. Procuramos, especificamente, saber: a) os textos produzidos pelos alunos a partir de uma proposta de escrita do livro didático de português (LDP) possibilitam extrapolar a roteirização na proposta?

Para construir uma resposta a essa interrogação, tomamos como corpus uma proposta narrativa do livro didático Português: Linguagem (CEREJA; MAGALHÃES, 2006, p. 41-42), $5^{\mathrm{a}}$ série (Nova Nomenclatura $6^{\circ}$ ano), manual do professor. Esse livro didático foi avaliado pelo PNLD $^{3}$ (BRASIL, 2008, 2009, 2010). Como critério de seleção, foi estabelecido apenas uma proposta ${ }^{4}$ narrativa do LDP, sendo esta aplicada em sala de aula para análise dos efeitos de roteirização na produção do texto dos alunos.

A esse respeito, apresentamos duas etapas de análise: na primeira, discorremos a respeito da existência de mecanismos de controle do trabalho escolar apresentados nos LDP nos exercícios de escrita aos dois usuários

2 Pesquisa 1: RIBEIRO, J. B. Mecanismos de controle do trabalho escolar em propostas de escrita narrativa em livros didáticos de português (1974-2009). 2013. 158 páginas. Dissertação (Mestrado em Linguística) - Programa de Pós-Graduação em Estudos da Linguagem, Universidade Federal do Rio Grande do Norte, Natal. Pesquisa 2: FARIAS, A. O. Efeitos da roteirização em atividades narrativas do livro didático de língua portuguesa: uma proposta de intervenção. 2015. 212 páginas. Dissertação (Mestrado Profissional em Letras) - Universidade Federal do Rio Grande do Norte, Natal.

3 Disponível em: <http://www.fnde.gov.br/index.php/pnld-guia-do-livro-didatico/2347-guiapnld-2008>. Acesso em: 12 jun. 2016.

4 A proposta narrativa do LDP escolhida faz parte do corpus de análise da dissertação de Ribeiro (2013), que foi formado por 63 livros didáticos do Ensino Fundamental, do $6^{\circ}$ ao $9^{\circ}$ ano. A pesquisadora fez um recorte no corpus inicialmente constituído (63 LDP) e selecionou 12 propostas de escritas de textos narrativos apresentados nos LDP de 1974 a 2009, para representar a sua análise. Para este estudo, então, fizemos um recorte no corpus de Ribeiro. Entre as 12 propostas narrativas analisadas, selecionamos 1 proposta de escrita narrativa para ser trabalhada no $6^{\circ}$ ano do Ensino Fundamental. A proposta narrativa escolhida pertence a um LDP já avaliado pelo PNLD/2008. 
: principais do livro: o professor e o aluno. O foco reside em observar

: situações de ensino que oferecem roteiro de instruções, supostos ideais a ser seguidos e imitados pelos alunos, presentes no manual do professor que, geralmente, apresenta orientações, sugestões, respostas aos exercícios e informações ao professor, ao lado da proposta de escrita, para nortear/ controlar a prática do professor no ambiente escolar. Em seguida, na segunda etapa, houve a aplicação dessa proposta narrativa nas turmas do $6^{\circ}$ ano do Ensino Fundamental II, em uma escola pública localizada na zona norte da cidade de Natal/RN, buscando demonstrar os efeitos que uma atividade de produção textual roteirizada provoca nos textos produzidos pelos alunos.

Teoricamente, mobilizamos o trabalho de Althusser (1985), que considera a escola como parte dos Aparelhos Ideológicos do Estado (AIE); buscamos também respaldo na concepção dialógica de Bakhtin (2009) de que a linguagem apresenta uma natureza constitutivamente dialógica; bem como na proposta de Geraldi (2010, 2011) da prática de produção textual.

Este artigo está estruturado em quatro seções, a saber: a introdução, na qual contextualizamos a temática, apresentamos o objetivo/questão norteadora e a metodologia utilizada. O aporte teórico, no qual discutimos em três subseções sobre: o LDP no contexto educacional e os mecanismos de controle; a relação dialógica da linguagem; e a terminologia da redação à produção textual. A análise do corpus, na qual descrevemos e analisamos os mecanismos de controle em uma proposta narrativa do LDP direcionada ao professor e ao aluno no contexto educacional; além disso, analisamos nos textos produzidos pelos alunos os efeitos da roteirização em atividades propostas pelo LDP. Por fim, apresentamos nossas considerações finais, em que recuperamos os resultados e tecemos os comentários interpretativos.

\section{Aporte teórico}

Como ancoragem teórica que sustentarão as análises, abordaremos as ideias de Althusser (1985), especificamente a discussão referente à escola como parte dos Aparelhos Ideológicos do Estado (1985), e a ideologia no interior da escola. Além disso, buscamos respaldo na concepção de diálogo proposta por Bakhtin (2009), e levantarmos alguns pontos acerca da terminologia da redação à produção textual, conforme Geraldi (2010, 2011). 


\subsection{O livro didático de português no Brasil}

O livro didático (LD) é um material de grande circulação nas escolas brasileiras, sendo, em sua maioria, originária do Programa Nacional do Livro Didático (PNLD), que distribui gratuitamente esses livros para as escolas públicas de todo o país. Como todo discurso deixa transparecer uma intenção, verificaremos em vários livros didáticos de português (LDP) produzidos no Brasil o ideário de seus autores e dos discursos que os constituem em vista do contexto em que tal texto se insere. Sendo assim, faz-se necessário entender a escola enquanto um aparelho ideológico do Estado e, no seu interior, a função de poder do livro didático.

Althusser (1985) afirma que, para manter sua dominação, a classe dominante gera mecanismos de perpetuação ou de reprodução das condições materiais, ideológicas e políticas de exploração. Entra, nesse processo, o papel do Estado que, por meio de seus Aparelhos Repressores - ARE (compreende: o Governo, a Administração, o Exército, a Polícia etc.) e dos Aparelhos Ideológicos de Estado (AIE), designam certo número de realidades e se apresentam sob a forma de instituições distintas e especializadas, que funcionam com base em uma ideologia. Assim, segundo esse autor, “as escolas, as igrejas, 'moldam' por métodos próprios de sansões, exclusões, seleção etc., não apenas seus funcionários, mas também suas ovelhas" (ALTHUSSER, 1985, p. 70).

A escola, que é parte integrante do AIE, torna-se para as crianças uma audiência obrigatória. Portanto, é na escola que a criança aprende os saberes práticos: "ler, escrever e contar, ou seja, algumas técnicas e instruções" (ALTHUSSER, 1985, p. 57). Por isso, com base na ideologia e nos AIE, a classe dominante gera mecanismos de reprodução das condições materiais, ideológicas e políticas de exploração.

Nesse contexto, o professor exerce a função de reprodução de relações sociais quando ensina teorias concebidas por outro sem nenhuma reflexão de sua prática pedagógica. Trata-se de um sujeito que opera com instrumentos e materiais não produzidos por ele, a partir de projetos que não conhece e de utopias em que não acredita. Isso porque necessita defender e transmitir interesses do Estado e nunca pode deter os meios de produção do trabalho escolar devido à ideologia dominante que rege o ensino. 
Sob essa ótica, Althusser (1985) define a escola como parte dos : Aparelhos Ideológicos do Estado que, por meio de sua ideologia, busca no ensino assegurar sua prática. Assim, podemos inferir que as propostas apresentadas nos Parâmetros Curriculares Nacionais (PCN), por exemplo, que repercutem no discurso apresentado no LDP para o processo de ensino e aprendizagem nas escolas brasileiras, têm como função a dominação de seu funcionamento com base em ideologias.

Se observarmos a organização interna do LDP, é possível perceber a padronização dos capítulos e a homogeneização das propostas de atividades, ao apresentar, nos diferentes níveis de escolarização, exercícios de escrita a partir de "roteiros de instruções" e padrões de textos, para ensinar o aluno a escrever, por exemplo. Além disso, no manual do professor, os autores apresentam notas sugestivas em letras pequenas, ao lado da proposta de produção escrita, para controlar e nortear a prática do professor. A ideologia do LDP, a partir da sua organização interna, leva-nos a crer que os exercícios propostos são, no geral, apresentados pelos autores com o intuito de controlar a escrita do aluno ao apresentar "roteiros de instruções" e notas sugestivas direcionadas ao professor. Dessa forma, a própria existência do livro já é um "mecanismo de controle".

\subsection{A relação dialógica da linguagem}

A linguagem apresenta uma natureza constitutivamente dialógica. Nesse sentido, baseamo-nos na concepção de diálogo proposta por Bakhtin (2009). Segundo esse autor, em sentido amplo, o dialogismo é o que constitui todo e qualquer ato verbal, não somente as interações face a face mas ainda toda comunicação verbal, de qualquer tipo que seja. Desse modo, "o discurso escrito é de certa maneira parte integrante de uma discussão ideológica em grande escala: ele responde a alguma coisa, refuta, confirma antecipa as respostas e objeções potenciais procura apoio etc." (BAKHTIN, 2009, p. 128).

Bakhtin enuncia que a língua tem a propriedade de ser dialógica. O dialogismo é considerado para o autor como característica essencial da linguagem, princípio constitutivo do discurso e condição de sentido. A relação dialógica apresentada pelo pensador russo considera que, em qualquer ato enunciativo, a presença do outro é imprescindível, é a 
condição do discurso. Esse diálogo se constitui na alternância de vozes entre os envolvidos no processo de interação verbal porque corporifica e representa os discursos de outros. O texto, seja ele verbal seja não verbal, permite a interação entre os indivíduos em situações discursivas. Portanto, a interação é a função primordial da linguagem. Os interlocutores, por meio do diálogo, constroem seus enunciados, expressam suas ideias e se definem ora falantes, ora ouvintes, influenciando o outro pelo seu discurso ou sendo influenciados por esse outro.

Nos estudos bakhtinianos, a língua não se constitui isoladamente em enunciados monológicos, visto que se dirige para um outro para que, juntos, possam estabelecer a relação interacional discursiva. Dessa maneira, o dialogismo se constitui na articulação heterogênea da língua, com base na interação verbal na qual o sujeito tem papel responsivo ativo, porque reflete sobre o caráter da resposta que a linguagem exige dos seus interlocutores.

A língua é social, com a presença de várias vozes, constituídas por meio de relações dialógicas entre diferentes vozes sociais. Apesar de os autores dos Livros Didáticos de Português (LDP) não serem colocados frente a frente com seus interlocutores definidos em situações comunicativas, buscaremos compreender quais são as vozes que permeiam esse texto. Isso porque, como afirma Bakhtin (2009, p. 101): "toda enunciação mesmo na forma imobilizada da escrita, é uma resposta a alguma coisa e é construída como tal. Não passa de um elo da cadeia dos atos de fala”. Dessa maneira, o enunciado para ele é propriamente um elo da cadeia muito complexa de outros enunciados já ditos.

Destacamos que, se todo discurso é atravessado por outros discursos e o sentido vai estar diretamente relacionado ao entrecruzamento das vozes ali presentes, será possível, por meio do dialogismo, verificar nos Livros Didáticos de Português o delineamento da voz do autor do LD no conteúdo do livro, mais especificamente nas orientações direcionadas ao aluno nas propostas de escrita desse material e ao trabalho do professor, usuário do livro, na escola básica.

\subsection{Da redação à produção textual}

Nesta seção, cabe levantarmos alguns pontos acerca da terminologia "Da redação à produção textual", devido a sua pertinência para este 
: trabalho. Os estudos realizados por Geraldi $(2010,2011)$ trazem uma breve : visão do deslocamento do ensino de redação para a produção de textos, explanando que não se trata de uma mera troca de terminologia. Essa passagem promove também veiculações a outras concepções de linguagem, de sujeito e de escrita, que subjaz ao ensino contemporâneo.

Nos anos de 1980, os docentes, antes acostumados às atividades de redação, "foram bombardeados com a expressão "produção de texto" (GERALDI, 2011, p. 19). Para o autor, essa mudança não corresponde à mera troca de termos, nem apreço por novas terminologias, mas implica no envolvimento de outras concepções.

A primeira concepção envolve o conceito do que é o sujeito, pois "Produzir implica alguém que produza" (GERALDI, 2011, p. 19). O autor afirma que nos anos 1960 houve o confronto entre duas visões de sujeito: de um lado, acreditava-se na ideia de um sujeito pronto, fonte do seu dizer (GERALDI, 2011), plenamente consciente do seu dito. Esse sujeito apropria-se da língua que, por sua vez, era também considerada pronta, acabada, imutável, com isso, organiza seus pensamentos e transmite a outros.

A segunda concepção, citada pelo autor, é o entendimento da sala de aula como lugar de interação verbal. Pensar nesse ambiente como um lugar de interação é considerá-lo como um espaço onde coabitam diferentes sujeitos, portadores de diferentes saberes - os saberes do vivido, trazidos por alunos e professores, frutos de suas experiências, de suas histórias. Portanto, a sala de aula é lugar de interação, de diálogos entre os sujeitos - professor e aluno - e seus saberes, que são confrontados com os conhecimentos advindos dos saberes da herança cultural. Isso implica dizer que o processo de ensino não é uma transmissão do conhecimento, pois o professor não ocupa o lugar exclusivo da fonte do saber, nem o aluno é receptáculo vazio, a ser preenchido.

A terceira concepção envolve o reconhecimento do texto como unidade de ensino/aprendizagem. Um texto não é uma "voz que clama no deserto" (GERALDI, 2011), portanto, dialoga com outros textos, constituindo-se numa constante intertextualidade sem a qual não existiria. Segundo o autor, esses textos que dialogam entre si, pelos mesmos temas, por diferentes pontos de vista, por transitarem concomitantemente numa 
mesma sociedade, compõem nossa herança cultural. Nesse sentido, considera-se que é dialogando com textos passados, textos presentes que : construímos os textos futuros. Nessa perspectiva, o aluno é concebido como um produtor de textos, e não fazedor de redação, e esse deslocamento implica que o aluno não é mais um quadro em branco a ser preenchido, ele passa a ser agente, ativo, participante desse constante diálogo com textos e com leitores.

$\mathrm{Na}$ quarta concepção, entende-se que só se aprende e ensina com textos. Considerando a sala de aula como lugar de interação verbal, alunos e professores confrontam-se, dialogam, correlacionam por meio de seus textos com saberes e conhecimentos. No sentido dado ao sujeito, "como herdeiro e produtor da herança cultural” (GERALDI, 2011, p. 23), alunos e professores aprendem e ensinam um ao outro, em um processo constante de interação com seus textos, para, a partir deles, construir novos contextos e situações, significando, compreendendo, reproduzindo, multiplicando os sentidos em circulação na sociedade.

Diante do exposto, ao pensar na substituição do termo "redação" por "produção de texto", segundo o autor, é preciso levar em consideração dois aspectos fundamentais que envolvem o processo da escrita: em primeiro lugar, ao se pensar em produção, implica em considerar que toda produção envolve suas condições, seus agentes de produção, seus instrumentos e também a maneira como é produzido um texto em sala de aula. A escrita não é um dom, portanto, pensar em produção é pensar em trabalho, que, por sua vez, não é fruto só de inspiração (GERALDI, 2010).

Quando se escreve, essa escrita se destina a alguém, que será o coenunciador desse processo. $\mathrm{Na}$ escola, essa função era exercida exclusivamente pelo professor, que iria corrigir as redações de seus alunos. O texto do estudante só tinha uma finalidade: ser corrigido. A partir dos exercícios de redação, o aluno ia sendo preparado, treinado, para um dia escrever fora dos muros escolares, ou ainda em situações escolares, como os vestibulares.

Nessa perspectiva, o autor ressalta que produzir textos implica no envolvimento de vários instrumentos de produção. Ao escrever, é preciso o agenciamento de "recursos linguísticos para enfrentar um tema, definir um projeto de dizer no interior deste tema, selecionar um gênero discursivo e 
: transacionar com o estilo próprio do gênero, o estilo próprio do autor e o : estilo suposto adequado para os interlocutores" (GERALDI, 2010, p. 167).

É no uso, na língua em funcionamento, na leitura de textos, refletindo e debatendo temas, esquematizando, anotando, elaborando intervenções, revisando conceitos e concepções que consiste a preparação para a escrita de um texto. Desse modo, é por meio dessa convivência com os textos, com as expressões, que aprendemos a mobilizar os recursos linguísticos, apontando para a reflexão sobre a língua e não em sua descrição, classificação.

Diante dessas considerações sobre a trajetória da redação à produção textual, os Parâmetros Curriculares Nacionais (PCN) são referenciais para o Ensino Fundamental e Médio de todo o país e têm a finalidade de formar escritores competentes, capazes de produzir textos coerentes, coesos e eficazes nas mais variadas situações. Os PCN apontam que a escrita não é uma atividade em si, mecânica. De acordo com esse documento, mais do que ter o domínio da língua padrão, a escolha de um determinado gênero requer que o produtor do texto incorpore: as dimensões discursivas, incluindo os interlocutores, as relações entre eles, as intenções e as especificidades de cada gênero. Assim, "ao produzir um texto o autor precisa coordenar uma série de aspectos: o que dizer, a quem dizer como dizer” (BRASIL, 2001, p. 75).

A escrita não é um dom, portanto, pensar em produção é pensar em trabalho e não em um produto da inspiração (GERALDI, 2010). O autor afirma que no processo de produção de textos está associado "o querer dizer do locutor, que sempre remete à relação com seus interlocutores, e o estilo próprio do sujeito que fala" (GERALDI, 2010, p. 168) que vai determinar quais recursos mobilizar na materialização de seu discurso. Logo, pensar em produção textual é considerar e valorizar o texto do aluno. É vê-lo como agente do processo, herdeiro e produtor de herança cultural. É atribuir à sala de aula o sentido de lugar de interação, onde sujeitos e textos se realizam na ação, no trabalho sobre e com a escrita.

Desse modo, Geraldi (2010) explica que, em relação à produção de textos, o professor precisa considerar uma variedade de indícios que indicam quais os conhecimentos já construídos por seu aluno. No processo de mediação, segundo o autor, o ideal seria partir do já sabido "para chegar a outros aspectos do tema e a outras formas de tratá-lo e de apresentá-lo" 
(GERALDI, 2010, p. 170). Sair do senso comum, fazendo a ponte entre o sabido e o potencial é a melhor forma de mediação do professor.

Esse autor nos explica que considerar as condições discursivas de produção é refletir que tudo o que há para dizer pode ser dito de múltiplas maneiras e nunca está terminado. Significa que trabalhar as diversas formas de dizer sobre um tema ou assunto é o caminho recomendado, para, na sala de aula, promover a guinada do exercício de redação para a produção de texto. Dessa maneira, o professor torna-se o coautor dos textos dos seus alunos, trabalhando juntos, refletindo juntos e ambos avançando, desenvolvendo suas capacidades na produção de novos textos.

\section{ANÁLISE DO CORPUS}

Nesta seção, faremos uma análise qualitativa e quantitativa de uma proposta de escrita narrativa do LDP que contempla roteiro de instrução para sua realização. Por meio dessa análise, tentamos responder à questão proposta para este estudo, a saber: os textos produzidos pelos alunos a partir de uma atividade de escrita do livro didático de português (LDP) possibilitam extrapolar a roteirização na proposta? Para isso, descreveremos os mecanismos de controle em uma proposta narrativa do LDP e além disso, mostraremos os efeitos que a roteirização presente na proposta de escrita do LDP provocou na produção do texto narrativo dos alunos.

\subsection{Análise qualitativa e quantitativa}

Nesta seção, faremos uma análise qualitativa e quantitativa dos resultados de um texto do gênero narrativo cujo título é "Conto maravilhoso - do oral ao escrito e vice-versa”. Para isso, no primeiro momento de análise, mostraremos uma proposta narrativa do livro didático de português (LDP), a fim de verificar os mecanismos de controle direcionados aos alunos e professores em uma proposta de escrita narrativa do livro didático Português: Linguagem (CEREJA; MAGALHÃES, 2006). Além disso, na segunda etapa de análise, mostraremos os efeitos que a roteirização presente na atividade provocou na produção do texto narrativo dos alunos. A seguir, apresentamos a proposta narrativa do Livro Didático selecionada e trabalhada em sala de aula. 
Os textos que voce produzira a seguir serào publicados num livro de contos que fara parte da mostra Histórias de hoje e sempre, proposta no capitulo Intervalo, e será lido por colegas de sua classe e de outras, por seus pais e demais convidados para o evento.

1. Escreva um conto maravilhoso, de acordo com as orientaçoes dadas a seguir.

a) Em cada lista de palavras abaixo, todas, com exceclo de uma, sugerem uma historia conhecida. Tal palavra representa um novo elemento, que quebra, de proposito, a sequéncia. Veja:

- menina - bosque - lobo - avo - helicóptero

- Cinderela - madrasta - principe - sapatinho de cristal - chule

- Bela Adormecida - principe encantado - conjunto de rock - bruxa boa

- Joto e Maria - uma casinha de doces - a bruxa - o forno - um pernil assado

- Pinóquio - os ladroes - um extraterrestre - a baleia - Gepeto

- Aladim - genio - princesa - lampada maravilhosa - Ali Baba e os quarenta ladróes

- Branca de Neve - principe - sete andes - madrasta - baile

b) Escolha uma lista e reinvente a história, incluindo nos acontecimentos o elemento novo correspondente a palavra que destoa das outras. Escolha quem será o heroi e quem fará o papel de vilao. Comece seu conto fazendo o herói ser vitima de uma armadilha planejada pelo vilâo, ou o contrario. Se quiser, de ao heroi (ou ao vilao) poderes mágicos. Procure criar um final inesperado, se possivel engracado.

c) Planeje como vai escrever seu conto maravilhoso: inicie-o pela expresslo Era uma vez ou outra que conduza a um tempo passado e impreciso. O narrador deve ser do tipo observador. Lembre-se de dizer como slo o herót, o viláo e o lugar em que ocorrem os fatos. Empregue a língua padrào. Ao terminar, de um titulo sugestivo a seu conto.

d) Faça um rascunho e so pusse seu conto a limpo depois de fazer uma revisio cuidadosa, seguindo as orientaçes do boxe Avalie seu conto maravilhoso (p. 20). Refaça o texto quantas vezes forem necessirias.

2. Crie livremente um conto maravilhoso, com personagens de sua preferéncia. Siga as orientaçoes constantes nos itens $\mathbf{c} \mathbf{e d}$.

3. Voce conhece uma parlenda infantil que se inicia pela frase "Cade o toucinho que estava aquir"? Nessa parlenda, conta-se uma história por meio de um jogo de palavras que aparecem encadeadas numa sequéncia. Esse processo narrativo $\ell$ o mesmo das chamadas historias sem fim, for-

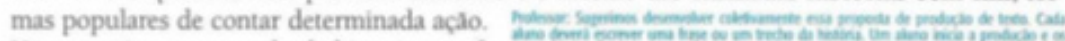
Ha, a seguir, um exemplo de historia sem fim, coletada na Inglaterra.

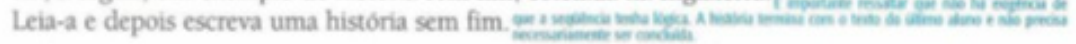

Fonte: CEREJA, W. R.; MAGALHÃES, T. C. Português: linguagens. $5^{\mathrm{a}}$ série. 4. ed. São Paulo: Atual, 2006. p. 41-42.

Na primeira etapa de análise, discorremos a respeito da existência de mecanismos de controle do trabalho escolar apresentados nos LDP nos exercícios de escrita aos dois usuários principais do livro: o professor e o aluno, em situações de ensino. Para tanto, fizemos uma leitura da proposta 
narrativa do LDP, no sentido de identificar a roteirização presente e contextualizar a análise. Observamos que a roteirização se apresenta em : comandos ou "sugestões" na linguagem verbal e também não verbal. A proposta traz orientações de como o aluno deve escrever seu conto, indicando, passo a passo, o caminho a ser seguido para sua produção. A esse gênero, que busca manter o controle da produção escrita, denominamos "roteiro de instrução".

É visível que, na atividade, o estudante deverá reinventar um conto maravilhoso, mas para cumprir essa tarefa terá de seguir as orientações dadas. Vejamos o primeiro item: "1) Escreva um conto maravilhoso, de acordo com as orientações dadas a seguir:”. No item “a”, é apresentada ao aluno uma lista de palavras que indica um conto maravilhoso já conhecido. A essa lista acrescenta-se um elemento que, no conto clássico não existia, quebrando propositalmente a sequência do conto tradicional, conforme se pode observar a seguir: "menina - bosque - lobo - avó - helicóptero; Cinderela - madrasta - príncipe - sapatinho de cristal - chulé; Bela Adormecida - príncipe encantado - conjunto de rock - bruxa boa".

No item "b", o autor do livro didático "solicita" que o aluno escolha uma das sequências e "reinvente" a história, acrescentando a essa "nova" história o elemento novo correspondente à palavra que destoa das outras. Em seguida, o autor, indica o passo a passo que o aluno deverá seguir:

a) escolha quem será o herói e quem fará o papel de vilão; b) comece seu conto fazendo o herói ser vítima de uma armadilha planejada pelo vilão ou ao contrário; c) "se quiser", dê ao herói (ou ao vilão) poderes mágicos; d) procure criar um final inesperado, se possível engraçado.

Essa roteirização apresenta as ideias que o aluno deverá abordar na produção do seu conto, sugere o que "tem a dizer".

No item "c", como a atividade proposta trata de um conto maravilhoso e, geralmente nesse gênero, nos contos tradicionais, nos modelos canônicos, o texto se inicia com a expressão "Era uma vez", o autor do livro didático "sugere" que os alunos iniciem seus textos com a expressão "Era uma vez" ou "outra que conduza a um tempo passado e impreciso". Isso se dá pelo mesmo motivo: seguir o modelo canônico que, na atividade proposta, embora o 
: autor do livro didático coloque a possibilidade ao aluno das opções "era : uma vez" ou outra expressão, percebe-se que a primeira está em negrito. Portanto, não é difícil para o leitor imaginar como os alunos provavelmente irão iniciar seus textos. Nesse item, o autor, em uma linguagem prescritiva (como em toda a atividade), propõe até mesmo as palavras com as quais os alunos devem iniciar seus contos.

$\mathrm{Na}$ primeira sequência de palavras no item "a" "menina - bosque lobo - avó - helicóptero", aparece, do lado direito da página, a figura de um helicóptero, com o piloto e um acompanhante que joga uma corda para salvar Chapeuzinho Vermelho das garras do Lobo Mau. A cena tem como representação de cenário o bosque. Consideramos esse desenho (linguagem não verbal), como mais uma instrução/controle que o autor do LDP exerce sobre o aluno, indicando como deve proceder, dessa vez, sugerindo qual o possível final, que inclua o elemento que destoa da narrativa tradicional do conto. $\mathrm{O}$ efeito dessa roteirização por meio do desenho terá seus reflexos não só na escrita do final do conto escrito pelos alunos como também na própria escolha da lista de palavras para a produção dos seus textos, como será percebido na análise dos primeiros textos produzidos e apresentados mais adiante.

A proposta se caracteriza principalmente pelo uso de uma linguagem prescritiva, cheia de imperativos, embora muitas vezes modalizada, dando a ideia de sugestão: "se quiser, dê ao herói (ou ao vilão) poderes mágicos", "Procure criar um final inesperado, se possível engraçado".

O emprego dos verbos impositivos, apresentados no roteiro do exercício, mais especificamente no início de cada alternativa, conduz a escrita do aluno e reforça o que denominamos de mecanismo de controle. Como podemos observar na atividade acima, nas alternativas: a) "Veja" a sequência das palavras sugeridas; b) "Escolha" uma lista; "Comece" seu conto; c) "Planeje" como vai escrever, "empregue" a variedade padrão, "dê" um título sugestivo; d) "Faça um rascunho e só passe seu conto a limpo depois de fazer uma revisão cuidadosa, seguindo as orientações do boxe. Avalie seu conto, maravilhoso (p. 20). Refaça o texto quantas vezes forem necessárias". Assim, além do tema sugerido (as sequências com os contos já conhecidos) e das ações dirigidas (veja, escolha, comece, dê, procure), o roteiro delimita as palavras que devem ser introduzidas na "versão" do aluno 
(helicóptero, chulé, conjunto de rock, pernil assado, um extraterrestre). Ou seja, compete ao aluno apenas executar o roteiro apresentado.

$\mathrm{Na}$ proposta, é ainda possível verificar o controle direcionado ao professor, na última sugestão da atividade de escrita que se refere à parlenda infantil (uma história por meio de um jogo de palavras que aparecem encadeadas numa sequência). Logo abaixo dessa proposta de escrita, aparece, em letras pequenas e azuis, a instrução:

Professor: Sugerimos desenvolver coletivamente essa proposta de produção de textos. Cada aluno deverá escrever uma frase ou um trecho da história. Um aluno inicia a produção e os demais continuam, ligando uma situação à outra. É importante ressaltar que não há exigência de que a sequência tenha lógica. A história termina com o texto do último aluno e não precisa necessariamente ser concluída (CEREJA; MAGALHÃES, 2006, p. 42).

Desse modo, observamos que o autor do LDP busca manter um controle da prática do professor e do fazer do aluno por meio de orientações.

A proposta apresenta aspectos também positivos, pois deixa claro para o aluno: o gênero, o possível interlocutor do texto, a divulgação e a circulação: "Os textos que você produzirá a seguir serão publicados num livro de contos que fará parte da mostra Histórias de hoje e sempre proposta no capítulo Intervalo e será lido por seus colegas de sua classe e de outras, por seus pais e demais convidados para o evento" (CEREJA; MAGALHÃES, 2006, p. 41, grifo do autor). Apesar de essa proposta apresentar uma lista de palavras que, de certa forma, induz o aluno à reprodução de um texto já conhecido, essa circulação marcada contribui para o aluno aprender a escrever em situações concretas e significativas.

Após essa reflexão, levamos a proposta narrativa do LDP - Conto maravilhoso - para a sala de aula $\left(6^{\circ}\right.$ ano A e $\left.6^{\circ} \mathrm{B}\right)$ e solicitamos a escrita pelos alunos, sem nossa intervenção. Nessa segunda etapa de análise, mostraremos os efeitos que a roteirização presente na proposta de escrita do LDP provocou na produção do texto narrativo dos alunos. Apresentamos, a seguir, sob uma abordagem quantitativa, tendo como corpus 58 (cinquenta e oito) textos produzidos pelos alunos, sendo 33 (trinta e três) no $6^{\circ}$ ano 
A do turno matutino e 25 (vinte e cinco) no $6^{\circ}$ ano $\mathrm{B}$ do turno vespertino.

Primeiramente, separamos os textos por sequência escolhida para fazermos um levantamento quantitativo, em relação à escolha das sequências. Isto é, para cada sequência, informamos quantos textos foram produzidos. Feito o levantamento, obtivemos o resultado mostrado no quadro a seguir.

QUADRO 1 - Resultado do levantamento obtido

\begin{tabular}{|c|c|}
\hline Sequência & $\begin{array}{r}\mathbf{N}^{\mathbf{0}} \\
\text { de textos }\end{array}$ \\
\hline 1- menina - bosque - lobo - avó - helicóptero & 38 \\
\hline $\begin{array}{c}\text { 2 -Cinderela - madrasta - príncipe - sapatinho de } \\
\text { cristal - chulé }\end{array}$ & 7 \\
\hline $\begin{array}{l}\text { 3-João e Maria - uma casinha de doces - a bruxa - o } \\
\text { forno - um pernil assado }\end{array}$ & $\mathbf{6}$ \\
\hline $\begin{array}{c}\text { 4-Branca de Neve - príncipe - sete anões - madrasta } \\
\text { - baile }\end{array}$ & $\mathbf{6}$ \\
\hline $\begin{array}{c}\text { 5-Aladim- gênio - princesa - lâmpada maravilhosa - } \\
\text { Ali Babá e os quarenta ladrões }\end{array}$ & 1 \\
\hline Total & $\mathbf{5 8}$ \\
\hline
\end{tabular}

Fonte: autoria própria

Durante a análise dos contos produzidos pelos alunos, contabilizamos que 47 produções textuais seguem somente os comandos, a roteirização presente na proposta do livro didático e recuperam o conto armazenado em suas memórias. Ou seja, reproduzem o conto clássico que lhes é mais familiar. E 11 textos criam uma nova versão, articulando a sequência de palavras dadas a novas informações, mesmo sem a mediação do professor.

De posse das produções dos alunos, fizemos uma análise descritiva e interpretativa. Como podemos observar no quadro acima, a maioria dos alunos escolheu para produção do conto a primeira sequência de palavras (menina - bosque - lobo - avó - helicóptero), tendo como corpus 38 textos (22 textos na turma A e 16 textos na turma B). Depois dessa etapa, procedemos à análise quantitativa e qualitativa, analisando os 38 textos produzidos pelos alunos, verificando os seguintes aspectos: a) quantos 
textos reproduziram o conto clássico; e b) quantos ousaram e escreveram um novo enredo, extrapolando assim, a roteirização proposta na atividade do livro didático, acrescentando novas informações a sua narrativa. Como resultado dessa análise, obtivemos o seguinte quadro:

QUADRO 2 - Resultado da análise

\begin{tabular}{|l|l|l|}
\hline Sequência & Reprodução & Produção \\
\hline $\begin{array}{l}1 \text { menina - bosque - lobo - } \\
\text { avó - helicóptero }\end{array}$ & 32 & 6 \\
\hline
\end{tabular}

Fonte: autoria própria

Atribuímos esse fato, possivelmente, a dois aspectos: a) foi o conto mais ouvido, assistido ou lido pelos alunos; e b) foi a forma como o autor do livro didático roteirizou a proposta. Nesse sentido, além da lista de palavras, os autores ainda acrescentaram, do lado direito da página, a figura de um helicóptero com um caçador e um passageiro dentro, jogando a corda e salvando Chapeuzinho Vermelho das garras do Lobo mau. Com isso, depreendemos que ao aluno foi sugerido um possível final, que incluía um elemento que destoava da narrativa tradicional. Para o aluno, seria mais "fácil" optar pela sequência que já mostrava como incluir na narrativa tradicional esse novo elemento.

Como vimos no primeiro momento de análise, a proposta de escrita do LDP apresentou mecanismos de controle que indicaram o passo a passo, por meio de roteiros, sugerindo início, final da história, tema, ações e até desenhos, como se só houvesse uma maneira de proceder na produção de um texto. Podemos comprovar essa ideia com base nas narrativas analisadas, quando foi possível perceber que a maioria produziu os seus textos exatamente como o livro didático determinou e, muitas vezes, na mesma ordem estabelecida pelo material.

Assim, como resultado dos efeitos da roteirização presentes na atividade proposta do LDP, na maioria dos textos produzidos, houve uma homogeneização nas narrativas, ou seja, os alunos, em sua maior parte, seguiram o comando da atividade e recuperaram uma versão já conhecida (a dos Irmãos Grimm), acrescentando a palavra helicóptero ao final da história, como sugerido pelo desenho da atividade. Com isso, a maioria dos 
: textos teve a mesma representação do conteúdo, o que comprometeu o : que eles tinham a dizer. Para exemplificar, trazemos dois textos produzidos pelos alunos (mencionamos as iniciais do nome), em atendimento à proposta (reprodução do conto clássico), e um texto (produção - extrapola a roteirização).

\section{Quadro 3 - Texto 1}

\section{Sem título}

1 Uma menina camiando pela a floresta. Esa minina era achapeuzinho vermelho ela

2 estava indo para acasada vovó i então um lobo apareceu. Ela continuou camiado pela

3 floresta e o lobo continuou a seguir o lobo pedil a sesta dela e ela coreu pela a 4 floresta. Ela chegou a casa da vovó o lobo tanben ja tinha chegado a casa da vovó o

5 lobo foi ate a cama da vovó e aengolil e a chapelzinho foi (...) a casa e dise quiolhos

6 grandes vose ten qui narigão você tem qui dentes enormes voce tem e então o lobo

7 tentou engolir a ela coreu e (...)um casador achapeusinho achamou ele pediu reforso

8 ao elicopitero com bala de tranquilisante o teteu e resgatou a vovó

FIN

Fonte: TJS

Observamos, assim, que o aluno se preocupou em utilizar todas as palavras sugeridas pela atividade na sequência escolhida (menina - bosque - lobo - avó - helicóptero), vejamos: linha 1 - menina e floresta; linha 2 vovó e lobo e linha 8 - helicóptero. Percebe-se que além de usar as mesmas palavras, o texto é construído colocando as palavras na mesma ordem dada pela proposta.

Outro aspecto observado que indica que o aluno seguiu o roteiro apresentado na proposta encontra-se nas linhas 7 e 8 , em que aparece o novo elemento na narrativa, o helicóptero, que é chamado pelo caçador. $\mathrm{Na}$ cena, o caçador pediu reforço ao helicóptero, que antes ser inanimado e foi personificado, porque o helicóptero desceu e resgatou a vovó. Porém, a entrada desse elemento novo não proporcionou um final inesperado na narrativa. $\mathrm{O}$ aluno apenas reproduziu o conto clássico que a sequência de palavras sugeria e acrescentou a palavra helicóptero ao final, repetindo o que atividade proposta também sugeria como possível final: o desenho do 
helicóptero, salvando Chapeuzinho Vermelho das garras do Lobo Mau.

$$
\text { Quadro 4-Texto } 2
$$

Chapeuzinho vermelho

1 Era uma vez uma menina que se chamava chapeuzinho vermelho um dia bem lindo

2 ensolarado a mãe dela mandou ela ir ate a casa da avó dela deixar alguns doces para ela

3 porque ela estava muito doente e chapeuzinho foi deixar os doces a mãe dela mandou ela ir

4 deixar os doces pelo caminho mais curto e chapeuzinho foi pela floresta que era mais longe

5 chegando bem perto ela encontrou um lobo muito feio o lobo perguntou o que você leva ai

6 nessa sexta chapeuzinho falou doces para a minha avó ela esta muito doente o lobo foi

7 embora pegou um atalho para a casa da avó quando chegou lá o lobo tinha ingulido a vovó

8 enteira o lobo se vestiu com a roupa da vovó chapeuzinho chegou e bateu na porta.toc.toc

9 quem éo lobo responde era chapeuzinho vermelho o lobo disse entre minha netinha

10 chapeuzinho disse trouxe alguns doces para você chapeuzinho disse que olhos grandes você

11 tem e para te ver melhor, que dentes grandes você tem e para morder melhor minha netinha

12 chapeuzinho percebeu que era o lobo e resolveu chamar uma pessoa. Ia passando um

13 helicóptero e chapeuzinho chamou o homem para tirar a vóvózinha o homem pegou uma

14 tesoura cortou a barriga do lobo tirou a vovó o lobo morreu eles viveram feliz para sempre

FIM

Fonte TMS: 
Os aspectos observados no Texto 2 , referentes à roteirização e seus : efeitos nos textos narrativos produzidos pelos alunos, não se diferem da análise do texto apresentado no Quadro 3, mas achamos relevante analisálo, mesmo que, para o leitor, torne-se repetitivo, como forma de refforçar nossos argumentos de que os alunos reproduziram a mesma história.

Observamos que o estudante, na construção de sua versão, seguiu o passo a passo proposto pela atividade narrativa: i) repetição de todas as palavras da sequência: linha 1 - menina; linha 2 - avó; linha 4 - floresta; linha 5 - lobo; e linha 13 - helicóptero; ii) linha 1 - o conto inicia-se com "Era uma vez", como colocado na proposta que destaca essa expressão em negrito, sugerindo as palavras que o aluno deve usar para iniciar seu conto; iii) linha 13 - usou o elemento novo no final da narrativa, mas novamente, nesse texto, percebe-se que esse elemento não deu um final inesperado ao conto do aluno, o final é o mesmo do Texto 1: o helicóptero salva a vovó e a Chapeuzinho Vermelho .

Assim, o aluno reproduz a mesma versão do conto clássico do Texto 1, em que temos a representação do vilão, o Lobo Mau, e a do herói, o homem e seu helicóptero, que, como nos mostra nas linhas 12 e 13 - "Ia passando um helicóptero". Ademais, percebe-se que a aluna não tinha argumentos para a presença do helicóptero no meio do caminho, uma vez que apresenta um elemento novo em versão já conhecida. Por isso, resolve o problema seguindo a sugestão dada pela atividade (por meio do desenho já citado acima) e afirma que o helicóptero ia passando por ali, na floresta, casualmente, onde passam lobos, meninas, os três porquinhos...

A proposta narrativa aplicada em sala de aula tem, como já vimos acima, o seguinte comando:

1) Escreva um conto maravilhoso de acordo com as orientações dadas a seguir:

a) Em cada lista de palavras abaixo, todas, com exceção de uma, sugerem uma história conhecida. Tal palavra representa um novo elemento, que quebra, de propósito a sequência. Veja: menina - bosque - lobo - avô - helicóptero

b) Escolha uma lista e reinvente a história, incluindo nos acontecimentos o elemento novo correspondente á palavra que destoa das outras. Escolha quem será o herói e quem fará 
o papel de vilão. Comece seu conto fazendo o herói ser vítima de uma armadilha planejada pelo vilão ou o contrário, etc. (CEREJA; MAGALHÃES, 2006, p. 41).

A atividade propõe que o estudante, a partir dessa lista de palavras que sugere uma história conhecida, nesse caso específico, o conto Chapeůinho Vermelho, reinvente a história acrescentando esse novo elemento que destoa da versão clássica, dando um final inesperado, se possível engraçado.

$\mathrm{Na}$ análise dos textos, observamos que provavelmente os alunos, no geral, tiveram dificuldades na compreensão do comando da proposta, pois, na verdade, a atividade orienta que façam uma nova versão com final inesperado, o que implicaria que esse aluno fosse construindo os argumentos de sua história e desse um final surpreendente. Isto é, o estudante se desprenderia daquela história já conhecida, do texto armazenado em sua memória, e construiria sua versão. Porém, na leitura dos textos selecionados dos alunos, percebemos que eles não reinventaram um conto, mas reproduziram a história já conhecida (no caso a versão dos Irmãos Grimm), resultando em uma versão do conto maravilhoso Chapeuzinho Vermelho, armazenada em suas memórias.

Isso se deu, possivelmente, pelo aspecto da roteirização presente na proposta, que além das instruções, passo a passo, indicando tema, ações, inseriu, do lado direito da página, uma figura do helicóptero com o piloto e um passageiro salvando a Chapeuzinho Vermelho das garras do Lobo Mau. Desse modo, acabou por sugerir como o aluno, no seu texto, introduziria o elemento novo da lista, promovendo assim uma homogeneização dos seus escritos.

Precisamos ressaltar que a proposta traz como condição desencadeadora para a produção uma lista de palavras acompanhada por uma gravura. Por conseguinte, o que se tem a dizer é uma história suscitada pela lista e por uma gravura, fazendo com que o aluno não relacionasse a nova versão às próprias vivências. A esse respeito, Geraldi (2003) afirma que qualquer ação pedagógica com os textos gerados dessa atividade requer que se leve em consideração: a) o próprio apelo ao recurso didático da lista e da gravura; e b) a própria demanda feita: uma história que se inventa a partir de uma lista e de uma gravura. Esses dois aspectos estão relacionados ao "conteúdo a dizer". Nesse sentido, vamos fazer uma análise comparativa 
: entre os 2 (dois) textos analisados anteriormente, tomando como roteiro : uma das condições para se produzir um texto "ter o que dizer".

Fazendo uma análise comparativa entre as versões, percebe-se que a representação do conteúdo é a mesma. Os alunos reproduziram uma história já conhecida e acrescentaram a palavra helicóptero a essa história, como proposto na atividade. Assim, a tarefa foi cumprida, tornando visível a homogeneização provocada nos escritos dos estudantes, pois eles contam a mesma história e as ações estão quase todas na mesma ordem. Desse modo, o que se tem a dizer foi anulado nessa atividade.

Para se comprovar, basta observar a sequência dos acontecimentos nos textos produzidos pelos alunos, é fácil perceber que eles seguiram o mesmo roteiro e na mesma ordem dada pelo autor do livro didático em sua proposta: "menina - bosque - lobo - avô - helicóptero". Inclusive os dois textos, analisados nesta pesquisa, utilizam o elemento novo (o helicóptero), na fase de resolução da narrativa. Porém, como os alunos não construíram uma nova versão do conto Chapeu₹inho Vermelho, mas escreveram a mesma história presente nas suas memórias, como acrescentar esse elemento novo nas sequências de argumentos da história já conhecida? - No meio do caminho tinha um helicóptero... tinha um helicóptero no meio do caminho. A proposta, mais uma vez, indicando e "facilitando" o caminho, aponta para a solução: coloca o desenho do helicóptero, no bosque, salvando a Chapeuzinho. Assim, os alunos contam a história já conhecida e finalizam:

Quadro 5 - Trecho final dos Textos 1 e 2

Texto 1 - O caçador pede reforço ao helicóptero, desceu e resgatou a vovó. (TJS)

Texto 2 - Ia passando um belicóptero e Chapeuzinho chamou o homem que salvou a sua vovozinha (TMS)

Fonte: TJS e TMS, respectivamente.

O exemplo que segue representa alguns dos textos produzidos que extrapolaram a roteirização pela sequência de palavras. Desse modo, foi observado o acréscimo de outros elementos contemporâneos à narrativa, numa tentativa dos alunos de construir uma nova versão relacionando o conto ao contexto. Entretanto, tiveram dificuldades em desenvolver o enredo, pois não tinham argumentos suficientes e acabaram repetindo o conto clássico. Vejamos: 
Quadro 6-Texto 3

Chapeuzinho vermelho

1 Era uma vez uma menina chamada chapeuzinho vermelho

2 Sempre ela ia deichar doces para o vovó dela. Mais um dia a mãe dela pediul para ela ir

3 deixar uns doces para a vó dela mais o lobo sentio o faro dos doces e ficou de tocaia mais

4 teve uma hora que ele apareceu na frente da bicicleta dela e perguntou pra onde você vai

5 com esses doces para casa da minha vó e ai entrou na floresta e saiu correndo e tentando

6 chegar na casa da vó dela mais o lobo era mais rápido e chego na casa da vo dela antes dela

7 pegou a vovozinha escondeu a vovozinha no armário passou a fita na boca dela para ela ficar

8 calada ai a chapeuzinho vermelho chegou mais antes ele tava se vestindo para enganar a

9 chapeuzinho vermelho ai o lobo se alevanta abril a porta mais o helicóptero aparesseu

10 salvou a vovozinha prendeu o lobo e salvou chapeuzinho vermelho e fim.

(THS)

Fonte: THS

Percebe-se que o estudante acrescentou outras palavras que possivelmente fazem parte do seu contexto - como se pode ver nas linhas 3 e 4: tocaia e bicicleta. A nosso ver, isso significa que o aluno compreendeu que a atividade pedia para criar uma nova versão e, provavelmente, possui conhecimentos prévios do que seja uma versão de uma história. No entanto, talvez por falta de outras leituras, demonstra dificuldades em articular esses elementos novos ao seu enredo, pois acrescenta as palavras, mas permanece preso à narrativa clássica. Ou seja, se retirar as palavras "tocaia" e "bicicleta" do seu texto, não altera o conteúdo desenvolvido. 


\section{CONSIDERAÇÕES FINAIS}

Este trabalho surgiu de uma preocupação prática com a aprendizagem da escrita em contexto escolar. Nosso objetivo mais geral foi investigar os efeitos que os mecanismos de controle provocam nos textos dos alunos. Procuramos, especificamente, saber: a) os textos produzidos pelos alunos a partir de uma proposta de escrita do livro didático de português (LDP) possibilitam extrapolar a roteirização na proposta?

Como primeiro aspecto de análise, observamos a existência de mecanismos de controle do trabalho escolar apresentado no LDP na proposta de escrita voltada para os dois usuários principais do livro: o professor e o aluno. Os dados analisados apontaram que a atividade narrativa proposta pelo LDP oferece roteiro de instruções para a escrita do conto, com desenhos e informações ao professor, ao lado da proposta de escrita, para nortear/controlar a sua prática no ambiente escolar. No segundo momento de análise, buscando demonstrar os efeitos que uma atividade de produção textual roteirizada provoca nos textos produzidos pelos alunos, quando aplicada sem a mediação do professor, resultaram na homogeneização dos textos.

Como o LDP exerce grande importância nas escolas brasileiras, sabemos que a proposta de escrita que sugere "roteiro de instrução" de um texto-fonte seria um treino de escrita e não uma ferramenta adequada para formar alunos proficientes de textos. Nesse contexto, observamos, nos Textos 1 e 2, que os alunos apenas seguiram a roteirização, ou seja, por si sós não compreenderam a proposta narrativa, não sabiam como reinventar o conto maravilhoso, não conseguiram se desprender da história clássica. Já o Texto 3 extrapola a roteirização pela sequência de palavras, sendo observado o acréscimo de outros elementos contemporâneos à narrativa, pelo autor, numa tentativa de construir uma nova versão relacionada ao seu contexto. No entanto, o aluno, no Texto 3, teve dificuldade em desenvolver o conto por não ter argumentos suficientes e, por fim, acabou repetindo o conto clássico.

Segundo Geraldi (2010), é preciso mais trabalho quando se pensa em produção. Nesse sentido, uma atividade como a apresentada neste estudo solicita ao aluno que produza um texto, como se, para produzir, bastasse ao aluno ter inspiração, criando-se a ilusão de que ao estudante compete seguir 
as indicações e colocar em sua história a palavra nova (como, por exemplo, helicóptero) e terá construído uma nova versão para o conto já conhecido.

Nesse processo de produção de textos, está associado "O querer dizer do locutor, que sempre remete à relação com seus interlocutores, e o estilo próprio do sujeito que fala" (GERALDI, 2010, p. 168) que vai determinar quais recursos mobilizar na materialização de seu discurso. Desse modo, ninguém reinventa uma história do nada, é preciso a construção de argumentos sólidos. Para isso, devem-se buscar outras vozes que construíram versões anteriores, trabalhando a multiplicidade de textos.

Nesse contexto, pensar em produção textual é considerar e valorizar o texto do aluno. É vê-lo como agente do processo, herdeiro e produtor de herança cultural. É atribuir à sala de aula o sentido de lugar de interação onde sujeitos e textos se realizam na ação, no trabalho sobre e com a escrita.

Acreditamos que o trabalho do professor como mediador - entre o livro didático e o aluno -, nas situações de prática de escrita, possibilita ao aluno extrapolar os mecanismos de controle apresentados no LDP, a partir de intervenções nos textos dos alunos, para minimizar as lacunas existentes em propostas de escrita em livros didáticos de Português para melhorá-las ou complementá-las, de acordo com as necessidades dos seus alunos.

A esse respeito, os estudos de Geraldi (2011) sobre a mediação do professor no processo de produção textual orientam ensinar a escrever a partir da elaboração de estratégias que possibilitem ao aluno o desenvolvimento de suas habilidades. Para que os alunos se tornem autores dos seus textos, é preciso da mediação do professor. Assim, refletindo juntos - professor e aluno - sobre seu vivido, torna-se possível estabelecer relações com o vivido, bem como novas relações com o já produzido. É nesse aspecto que a mediação do professor é fundamental para fazer a diferença no contexto de ensino, mas esse enfoque será assunto para outro artigo.

\section{REFERÊNCIAS BIBLIOGRÁFICAS}

ALTHUSSER, L. Aparelhos Ideológicos de Estado: nota sobre os Aparelhos Ideológicos de Estado (AIE). 2. ed. Tradução de Walter José Evangelista e Maria Laura Viveiros de Castro. Introdução crítica de José Augusto Guilhon Albuquerque. Rio de Janeiro: Graaal, 1985. 
BAKHTIN, M. Marxismo e filosofia da linguagem: problemas fundamentais : do método sociológico na ciência da linguagem. Tradução de Michel Lahud e Yara Frateschi Vieira. São Paulo: Hucitec, 2009.

BRASIL, Secretaria da Educação Fundamental. Parâmetros Curriculares Nacionais: introdução aos Parâmetros Curriculares Nacionais. Secretaria de Educação Fundamental. Brasília: MEC/SEC, 2001.

BRASIL. Ministério da Educação e do Desporto. Programa Nacional do Livro Didático (PNLD). MEC, Brasília. Disponível em: http://www. mec.gov.br, < <http://www.fnde.gov.br/index.php/pnld-guia-do-livrodidatico/2347-guia-pnld-2008>. Acesso em: 12 jun. 2012.

CEREJA, W. R.; MAGALHÃES, T. C. Português: linguagens, $5^{a}$ série. 4. ed. São Paulo: Atual, 2006. Manual do Professor.

FARIAS, A. O. Efeitos da roteirização em atividades narrativas do livro didático de língua portuguesa: uma proposta de intervenção. 2015. 212 páginas. Dissertação (Mestrado Profissional em Letras) - Universidade Federal do Rio Grande do Norte, Natal.

GERALDI, J.W. Da redação à produção textual. In: GERALDI, J.W.; CITELLI, B. (Coord.). Aprender e ensinar com textos de alunos. 7. ed. São Paulo: Cortez, 2011a.

GERALDI, J.W. A aula como acontecimento. São Carlos: Pedro e João, 2010.

GERALDI, J.W. Portos de passagem. 4. ed. São Paulo: Martins Fontes, 2003.

RIBEIRO, J. B. Mecanismo de controle do trabalho escolar em propostas de escrita narrativa em livros didáticos de português. 2013. 158 páginas. Dissertação (Mestrado em Linguística) - Universidade Federal do Rio Grande do Norte, Natal. 